\title{
Review
}

\section{Benefits of fecal microbiota transplantation: A comprehensive review}

\author{
Muluneh Ademe ${ }^{1}$ \\ ${ }^{1}$ Department of Microbiology, Immunology and Parasitology, College of Health Sciences, Addis Ababa University, \\ P.O. Box 9086, Addis Ababa, Ethiopia
}

\begin{abstract}
A growing body of literatures showed the interaction of dysbiotic gut with a wide range of disorders, and the clinical use of fecal microbiota transplantation (FMT) shifted from infectious disease to non-communicable disorders. Despite the promising therapeutic benefits of FMT, the exact mechanisms through which fecal recipients benefit from the fecal intervention are not well understood. However, owing to the advantages of having a healthy gut microbiome, possible mechanisms of actions of FMT has been described. On the one hand, through direct ecological competition, FMT may potentially stimulate decolonization of pathogenic microorganisms and increase host resistance to pathogens. Moreover, following dysbiosis, abnormal microbial colonization of the gastrointestinal tract may also cause excessive or dysregulated immune response, resulting in chronic inflammation and the development of mucosal lesions. In this regard, repopulating gut microbiome through FMT helps to restore immune function and reduce host damage. On the other hand, FMT helps to restore essential metabolites used for host metabolism, including short-chain fatty acids (SCFA), antimicrobial peptides (AMP), bacteriocins and bile acids. Therefore, in this review, the existing evidences regarding the mechanisms of action, current opportunities and challenges of FMT will be described.
\end{abstract}

Key words: Fecal transplantation; colonization resistance; mechanisms; stool bank; challenges.

J Infect Dev Ctries 2020; 14(10):1074-1080. doi:10.3855/jidc.12780

(Received 09 April 2020 - Accepted 05 July 2020)

Copyright (C) 2020 Ademe. This is an open-access article distributed under the Creative Commons Attribution License, which permits unrestricted use, distribution, and reproduction in any medium, provided the original work is properly cited.

\section{Introduction}

Fecal microbiota transplantation (FMT), also known as fecal transplantation, is the transfer of stool from a healthy donor into patient's gastrointestinal tract to restore the composition of recipient's gut microbiota [1]. The use of fecal material to treat diseases dates back to the $4^{\text {th }}$ century in China where the stool products were used to treat food poisoning, febrile disease and typhoid fever [2]. During that time, the fecal materials were given to patients labeled with unique names such as 'yellow soup' to avoid patients' repugnance [2,3]. Afterward, the use of fecal infusion as a therapeutic agent showed enormous progress (Table 1).

In the 17th century, an Italian anatomist described the use of enteric flora transplantation in veterinary medicine [2]. During World War II, fresh and warm camel faeces were reportedly used by soldiers as a remedy for bacterial dysentery [4]. In 1958, a patient with pseudomembranous colitis was successfully treated by the use of faecal enemas [5]. Later in 1989, an exchange of bowel flora on a 45 year old male with refractory ulcerative colitis (UC) was performed showing full and lasting clinical recovery after FMT treatment [6]. Over the last decades, faecal transplantation has received increased scrutiny. FMT was for the first time included into the IDSA/SHEA guidelines of 2010 [7]. Then, it was listed as a potential therapy for multiple Clostridioides difficile infection (CDI) recurrences in later guidelines [8]. However, despite the promising therapeutic benefits of FMT, data regarding the mechanisms through which fecal recipient benefit from the intervention is scarce. In this regard, this review includes available evidences to show the possible mechanisms of action of FMT. Moreover, the current opportunities and challenges of FMT will be discussed.

\section{Mechanisms of action of FMT}

Dysbiosis, which is an imbalance in the gut microbial community, results in the disturbance of several metabolic pathways that influence mechanical and immunological processes both in and outside the intestine. In this regard, gut microbiome dysbiosis leads to different disease conditions [9]. So far, a wide variety of medical therapeutic strategies did not present satisfactory clinical effects in correcting dysbiosis associated disorders [3]. Conversely, FMT emerged with a promising therapeutic potential for a variety of disease conditions [1]. Based on the available evidences, fecal recipients may benefit from the 
intervention through different mechanisms, including but not limited to colonization resistance, restoration of metabolites and restoration of immune function.

\section{Colonization resistance against pathogens}

The healthy microbiota provides protection against invading bacterial pathogens through colonization resistance which refers to the ability of commensals to prevent the colonization and overgrowth of intestinal pathogens [9]. The intestinal epithelium is represented by a monolayer of cells joined through tight junctions which plays a complex role in mucus production and immune response [10]. Ever since birth, the commensal flora attaches to the intestinal mucus, occupying all available spaces and impeding entero-pathogenic colonization [11]. On the other hand, the microbiota inhibits intestinal colonization by bacterial pathogens through nutrient competition. Mucins and dietary complex carbohydrates are essential intestinal nutritive resources to which commensal species have adapted through specific metabolic pathways. Enteropathogens frequently use nutritious sources offered by commensal species and pathogenic germs that are unable to metabolize these sources are frequently eliminated [12].

Nowadays, decolonizing pathogenic microorganisms by repopulating the gut with a healthy microbiome is becoming a therapeutic option for different diseases [13]. One good example, in this regard, is the application of FMT for the treatment of CDI. It has been well described that dysbiosis of gut characterized by the loss of diversity and richness of the microbiota predisposes a person to colonization of $C$. difficile [14]. The outgrowth and toxin production of the bacteria is associated to the pathology which ranges from mild diarrhea to severe pseudomembranous colitis and death [15]. Regardless of treatment with antibiotics, about $20 \%$ to $60 \%$ of patients treated for CDI will have recurrences, and the recurrence is related to inadequate recovery of the gut microbiota [16]. For this reason, repopulating the gut microbiome through FMT is shown to be the best therapeutic option for CDI which improves the cure rates to $90-92 \%[17,18]$. Moreover, by decolonizing the pathogenic bacilli through FMT, the mortality rates of severe CDI was decreased to $12 \%$ $(8 / 66)$ compared to the standard care of antibiotic treatment $(42 \%, 19 / 45)(\mathrm{P}<0.0003)$ [19]. Multi-drug resistant bacteria were also successfully eliminated through colonization resistance [20]. In a randomized controlled trial (RCT), FMT intervention demonstrated decolonization of carbapenem resistant Enterobacteriaceae (CRE) and extended-spectrum beta-lactamase (ESBL) producers in $41 \%(9 / 22)$ of patients who received a five-day course of oral antibiotics followed by FMT compared to $29 \%(5 / 17)$ of patients who didn't receive an intervention $(\mathrm{OR}=1.7$, 95\% CI 0.4-6.4) [21]. Moreover, vancomycin-resistant Enterococcus (VRE) was decolonized through FMT $[22,23]$. Therefore, through direct ecological competition, FMT may potentially stimulate decolonization of pathogenic microorganisms and increase host resistance to pathogens [24].

\section{Restoration of immune function}

As a person grows, the microbiota shapes the development of the immune system, and the immune system shapes the composition of the microbiota. This communication and mutual regulation is maintained throughout life and is the key for a healthy interaction between the microbiota and the immune system [25]. In normal physiologic conditions, the immune system promotes the growth of beneficial microbes and helps maintain a stable microbial community, while in return, a healthy microbiota produces molecular signals that support the development of immune cells and contribute to the fine tuning of immune responses [26]. It is estimated that about $70-80 \%$ of immune cells are located in the gut [27]. In this regard, well developed gut microbiota populations are associated with improved health. A healthy crosstalk between the gut microbiota and the immune system supports protective

Table 1. Major developments in the application of FMT.

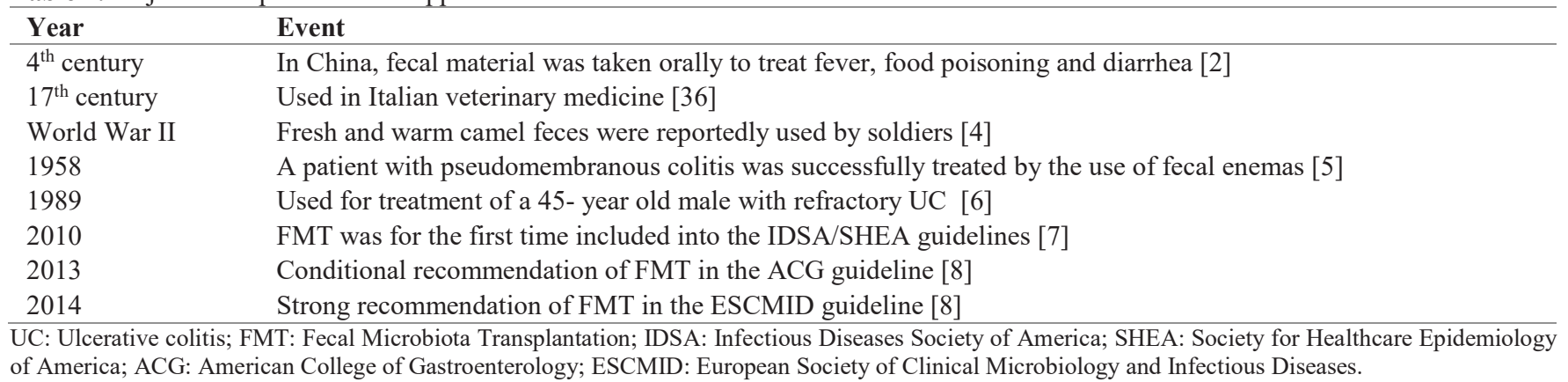


responses against pathogens, promotes tolerance to harmless microbes and their products, and helps maintain self-tolerance [28].

Altered intestinal microbial composition (dysbiosis) activates aggressive mucosal immune responses which results in chronic inflammation and the development of mucosal lesions [29]. This dysbiosis impairs the function of regulatory immune cells, which normally promote mucosal homeostasis. Normalizing and maintaining immune cell function by correcting dysbiosis through FMT provides a promising approach to treat some diseases. Early in 1998, a patient with UC who had active inflammation of the colon was treated through FMT and symptoms disappeared for 6 months after treatment [30]. In animal model of irradiated mice, FMT improved the peripheral white blood cell counts and increased the survival rate of mice [31]. The efficacy of cancer immunotherapy in epithelial tumors was also augmented by FMT which restored the immune cells [32].

\section{Restoration of metabolites}

Gut microbiome facilitates the production of metabolites with critical properties for host metabolism, including short-chain fatty acids (SCFA), antimicrobial peptides (AMP), bacteriocins and secondary bile acids [9]. SCFAs such as propionate, acetate, and butyrate are produced by the gut microbiota through fermentation of indigestible starches and complex sugars [9]. These SCFAs promote protection by enhancing barrier function and proliferation of gut epithelial cells. By decreasing epithelial permeability, SCFAs oppose bacterial and LPS translocations [33]. Furthermore, SCFAs decrease induction of proinflammatory cytokines and provide protection from colonic inflammation [28].

A growing body of literatures showed that alterations in the level of SCFAs correlate with some disease conditions. Plus, restoration of metabolites through FMT was significantly associated to an improved clinical prognosis. For instance, a decrease in butyrate and butyrate-producing bacterium has been observed in patients with UC, and through FMT, the level SCFAs was restored in patients who are in remission [34,35]. Likewise, the risk of steroidrefractory Graft-versus-host disease (GVHD) was indicated to be influenced by host-microbiota alterations which decrease butyrate production and potentially contributing to a pro-inflammatory state of the intestine [36,37]. In this regard, the chances of developing GVHD were shown to decrease after FMT which helps to restore in butyrate-producing intestinal microbiota. In a recent prospective open-label study, 13 patients were treated with FMT capsules after hematopoietic cell transplantation (HCT) to restore their intestinal microbiome diversity and only two patients developed acute gastrointestinal GVHD. Moreover, the 12-months overall survival and progression-free survival was $85 \%$ [38].

The other metabolites in which their production is controlled by intestinal microbiota are AMPs, bacteriocins and bile acids. AMPs, such as angiogenins, cathelicidin and defensines are innate immune effector molecules with bactericidal, anti-inflammatory and anti-endotoxinic properties. Bacteroides thetaiotaomicron and Listeria innocua are the main species of the microbiota that induce AMPs [39]. Cell wall active bactericidal polypeptides generically called bacteriocins, which are mainly produced by Eubacteria and Archaea of the gut commensal flora, significantly limit the colonization of pathogenic microorganisms, including multidrug resistant enterococci, $L$. monocytogenes, C. difficile, Staphylococcus aureus and other pathogens [40]. Primary bile acids are also essential antimicrobial agents [41]. In this regard, low concentrations of AMPs, primary bile acids and bacteriocins were shown to correlate with reduced antimicrobial function, favoring bacterial overgrowth and translocation [41-43]. Therefore, re-establishment of dysbiotic commensal intestinal communities through FMT helps to restore essential metabolites.

\section{Current opportunities of FMT}

Wide range of clinical applications

On the basis of the concept of repopulating the gut with a healthy microbiome, FMT has been successfully used in the treatment of infectious diseases. However, in recent years, the existing evidences showed the interaction of dysbiotic gut with a wide range of disorders, including but not limited to cancer [31,32], obesity and diabetes mellitus [44], inflammatory bowel disease (IBD) [13], autism spectrum disorder [45], multiple sclerosis (MS) [46], atherosclerosis and hypertension [47], GVHD [48], Parkinson's disease [49], Hepatic encephalopathy [50] and Nonalcoholic fatty liver disease (NAFLD) [51]. In this regard, the clinical use of FMT shifted from infectious disease to non-communicable disorders and the range of its applications extended rapidly [24]. Currently, more than 300 studies are evaluating FMT for various indications, primarily gastrointestinal, but also for neurologic, behavioral, and metabolic conditions [52]. 


\section{Availability of stool banks}

Despite the growing interest in using FMT for patient treatment and clinical investigation, availability of healthy donors for each recipient has remained the challenge. The use of patient-directed donor stool incurs treatment delays owing to the time required for sourcing, screening, and testing donors, with resultant increased costs and scheduling problems [53,54]. In this regard, standardization and easy access to donor feces suspensions is needed and using universal donors for FMT has emerged more convenient. The healthy volunteer donors are screened, standardized products are generated, and the products are stored after freezing [55]. These products can be delivered to recipients rapidly when needed.

A stool bank provides high-quality, ready-to-use donor feces suspensions from a prescreened and welldefined donor pool. This enables easy and costeffective fecal transfusion. Moreover, the observed comparable efficacy of frozen feces suspensions as that of fresh suspensions $[36,56]$ suggests the advantage of stool banking. As decreased microbial diversity is considered a possible cause of diseases of an altered microbiome, using fecal material from multiple healthy donors could theoretically enhance the therapeutic efficacy of FMT [13]. Stool banks such as OpenBiome and the Netherlands Donor Feces Bank (NDFB) have emerged owing to the cost-effectiveness and convenience of using fecal material from universal donors $[13,36]$.

\section{Challenges in FMT}

\section{Labor intensive donor screening}

Selection of an adequate donor is the key step in FMT. Standard donor screening protocols should be set up to lower the risks of infection transmission from the donor to recipient. Despite institutional variations, there are existing accepted protocols for donor screening (Table 2) suggested by the guidelines in the United States and European consensus conference to use a donor questionnaire to meet the exclusion and inclusion criteria [57,58]. However, it's often challenging to recruit the potential healthy donor. So far, a spouse or close relative was historically considered as an ideal donor for FMT [15]. Because of shared environmental risk factors, fecal material from the spouse might minimize the risk of infection transmission. Moreover, adaptive immunity in the mucosal immune system might present more tolerance [15]. Nevertheless, in diseases like IBD in which genetics plays a contributing factor, unrelated FMT volunteer donors are recommended than close relatives [59]. Usually, obtaining fecal donors who pass the rigorous screening test is challenging. For instance, Hota et al. reported that only 2 of $322(0.6 \%)$ prospective stool donors passed the screening for FMT stool donor program [60].

\section{Risk of unpredicted long-term outcomes}

Based on current evidences, FMT is viewed as a generally safe therapeutic method. Most immediate adverse events are self-limiting gastrointestinal symptoms which resolve within 1-2 days [61]. However, due to the short post-FMT follow-ups, the long-term outcomes of FMT have not been completely comprehended [13]. Aside from standardization of donor screening and clear protocols for adverse events monitoring, there will be risk of disease transmission of unrecognized infectious agents that cause illness years later [3]. Due to alterations in the gut microbiota, FMT may also lead to induction of chronic diseases such as obesity, diabetes, atherosclerosis, IBD, asthma, autism and other disease conditions [3,13,59]. Furthermore, some bacterial species, including Enterococcus faecalis, Escherichia coli and Bacteroides fragilis are associated to cancer [62]. In this regard, FMT may pose a risk of developing cancer. In line with this, the report from Wong et al. showed that the fecal microbiota from patients with colon cancer promoted tumorigenesis in germfree and carcinogenic mice [63].

In rare cases, bacteremia associated to FMT may cause serious problems and even death. So far, two deaths have been reported due to the side effects of FMT delivering procedures through mid-gut [64]. Recently, the New England Journal of Medicine published the case report on the first person known to die as a result of a fecal transplant in US [52]. The death

Table 2. Suggested screening tests for potential donors of FMT.

$\begin{array}{ll}\text { General conditions } & \text { Age (18-65 year), BMI }\left(18.5-25.0 \mathrm{~kg} / \mathrm{m}^{2}\right), \text { complete blood count, liver function test, ESR [3,13] } \\ \text { Medical history } & \begin{array}{l}\text { Past/current disease, current medication, antibiotics used in the past } 3 \text { months, surgery/tattooing/blood } \\ \text { transfusion in the past } 3 \text { months, high risk sexual behavior, raw meal in the past } 1 \text { week [3,52,57,65] }\end{array} \\ \text { Microbial screening } & \begin{array}{l}\text { Bacteria (Clostridioides difficile, Yersinia, Campylobacter, Shigella, Salmonella, enteropathogenic } \\ \text { Escherichia coli), viruses (Hepatitis (A, B, and C), HIV1, HIV2, Cytomegalovirus, Epstein-Barr virus, } \\ \text { rotavirus, adenovirus, enterovirus, norovirus, astrovirus), parasites (Giardiasis, Amoebiasis, stool } \\ \text { ova/parasites examination) [13,57,58] }\end{array}\end{array}$

BMI: Body-mass Index; ESR: Erythrocyte Sedimentation Rate; HIV1: Human Immunodeficiency Virus type 1; HIV2: Human Immunodeficiency Virus type 2 . 
occurred on a 73-year-old man who developed a fatal infection from ESBL-producing $E$. coli that were in the donor's stool sample [52].

\section{Conclusion}

Fecal microbiota transplantation emerged as a safe and promising therapeutic approach for infectious and non-infectious disorders. Though the data are scarce, there are evidences that FMT recipients may benefit from the intervention by one, or a combination of the following mechanisms: colonization resistance, restoration of metabolites and restoration of immune function. Despite the encouraging results in a diverse disease conditions, there are emerging concerns regarding the application of FMT. Notably, the death case report in U.S sends a clear message that there is still unfinished work with regard to ensuring safe fecal transfusion. Hence, further standardization of donor screening is needed to reduce the risk of FMT to the minimum, and ensure the at most benefit of recipient from FMT.

\section{References}

1. Brandt LJ, Aroniadis OC (2013) An overview of fecal microbiota transplantation: techniques, indications, and outcomes. Gastrointest Endosc 78: 240-249.

2. Zhang F, Luo W, Shi Y, Fan Z, Ji G (2012) Should we standardize the 1,700-year-old fecal microbiota transplantation? Am J Gastroenterol 107: 1755-1756.

3. Wang JW, Kuo CH, Kuo FC, Wang YK, Hsu WH, Yu FJ, Hu HM, Hsu PI, Wang JY, Wu DC (2019) Fecal microbiota transplantation: Review and update. J Formos Med Assoc 118 Suppl 1: 23-31.

4. Lewin RA (2001) More on merde. Perspect Biol Med 44: 594 607.

5. Smits LP, Bouter KE, de Vos WM, Borody TJ, Nieuwdorp M (2013) Therapeutic potential of fecal microbiota transplantation. Gastroenterology 145: 946-953.

6. Borody TJ, George L, Andrews P, Brandl S, Noonan S, Cole P, Hyland L, Morgan A, Maysey J, Moore-Jones D (1989) Bowel-flora alteration: a potential cure for inflammatory bowel disease and irritable bowel syndrome? Med J Aust 150: 604.

7. Cohen SH, Gerding DN, Johnson S, Kelly CP, Loo VG, McDonald LC, Pepin J, Wilcox MH (2010) Clinical Practice Guidelines for Clostridium difficile Infection in Adults: 2010 Update by the Society for Healthcare Epidemiology of America (SHEA) and the Infectious Diseases Society of America (IDSA). Infection control and hospital epidemiology 31: 431-455.

8. Thabit AK, Alsolami MH, Baghlaf NA, Alsharekh RM, Almazmumi HA, Alselami AS, Alsubhi FA (2019) Comparison of three current Clostridioides difficile infection guidelines: IDSA/SHEA, ESCMID, and ACG guidelines. Infection 47: 899-909.

9. Ooijevaar RE, Terveer EM, Verspaget HW, Kuijper EJ, Keller JJ (2019) Clinical application and potential of fecal microbiota transplantation. Annu Rev Med 70: 335-351.
10. Kong S, Zhang YH, Zhang W (2018) Regulation of intestinal epithelial cells properties and functions by amino acids. Biomed Res Int Hindawi 2018: 1-10.

11. Huang JY, Lee SM, Mazmanian SK (2011) The human commensal Bacteroides fragilis binds intestinal mucin. Anaerobe 17: 137-141.

12. Ndeh D, Gilbert HJ (2018) Biochemistry of complex glycan depolymerisation by the human gut microbiota. FEMS Microbiol Rev 42: 146-164.

13. Kim KO, Gluck M (2019) Fecal microbiota transplantation: An update on clinical practice. Clin Endosc 52: 137-143.

14. Leong C, Zelenitsky S (2013) Treatment strategies for recurrent Clostridium difficile infection. Can J Hosp Pharm 66: 361-368

15. Bakken JS, Borody T, Brandt LJ, Brill JV, Demarco DC, Franzos MA, Kelly C, Khoruts A, Louie T, Martinelli LP, Moore TA, Russell G, Surawicz C (2011) Treating clostridium difficile infection with fecal microbiota transplantation. Clin Gastroenterol Hepatol 9: 1044-1049.

16. McDonald LC, Gerding DN, Johnson S, Bakken JS, Carroll KC, Coffin SE, Dubberke ER, Garey KW, Gould CV, Kelly C, Loo V, Sammons JS, Sandora TJ, Wilcox MH (2018) Clinical practice guidelines for Clostridium difficile infection in adults and children: 2017 update by the Infectious Diseases Society of America (IDSA) and Society for Healthcare Epidemiology of America (SHEA). Clin Infect Dis 66: 987-994.

17. Kassam Z, Lee CH, Yuan Y, Hunt RH (2013) Fecal microbiota transplantation for Clostridium difficile infection: systematic review and meta-analysis. Am J Gastroenterol 108: 500-508.

18. Quraishi MN,Widlak M, Bhala N, Moore D, Price M, Sharma N, Iqbal TH (2017) Systematic review with meta-analysis: the efficacy of faecal microbiota transplantation for the treatment of recurrent and refractory Clostridium difficile infection. Aliment Pharmacol Ther 46: 479-493.

19. Hocquart M, Lagier JC, Cassir N, Saidani N, Eldin C, Kerbaj J, Delord M, Valles C, Brouqui P, Raoult D, Million M (2018) Early fecal microbiota transplantation improves survival in severe Clostridium difficile infections. Clin Infect Dis 66: 645650.

20. Singh R, van Nood E, Nieuwdorp M, van Dam B, Ten Berge IJM, Geerlings SE, Bemelman FJ (2014) Donor feces infusion for eradication of extended spectrum beta-lactamase producing Escherichia coli in a patient with end stage renal disease. Clin Microbiol Infect 20: O977-O978.

21. Huttner BD, de Lastours V, Wassenberg M, Maharshak N, Mauris A, Galperine T, Zanichelli V, Kapel N, Bellanger A, Olearo F, Duval X, Armand-Lefevre L, Carmeli Y, Bonten M, Fantin B, Harbarth S, R-Gnosis WP3 study group (2019) A five-day course of oral antibiotics followed by faecal transplantation to eradicate carriage of multidrug-resistant enterobacteriaceae: a randomized clinical trial. Clin Microbiol Infect 25: 830-838.

22. Singh R, de Groot PF, Geerlings SE, Hodiamont CJ, Belzer C, Ten Berge IJM, de Vos WM, Bemelman FJ, Nieuwdorp M (2018) Fecal microbiota transplantation against intestinal colonization by extended spectrum beta-lactamase producing Enterobacteriaceae: a proof of principle study. BMC Res Notes 11: 1-6.

23. Dinh A, Fessi H, Duran C, Batista R, Michelon H, Bouchand F, Lepeule R, Vittecoq D, Escaut L, Sobhani I, Lawrence C, Chast F, Ronco P, Davido B (2018) Clearance of carbapenemresistant Enterobacteriaceae vs vancomycin-resistant 
enterococci carriage after faecal microbiota transplant: a prospective comparative study. J Hosp Infect 99: 481-486.

24. Wortelboer K, Nieuwdorp M, Herrema H (2019) Fecal microbiota transplantation beyond Clostridioides difficile infections. E Bio Medicine 44: 716-729.

25. Nicholson JK, Holmes E, Kinross J, Burcelin R, Gibson G, Jia W, Pettersson S (2012) Host-gut microbiota metabolic interactions. Science 336: 1262-1267.

26. Levy M, Thaiss CA, Elinav E (2015) Metagenomic cross-talk: the regulatory interplay between immunogenomics and the microbiome. Genome Med 7: 1-13.

27. Furness JB, Kunze WA, Clerc N (1999) The intestine as a sensory organ: neural, endocrine, and immune responses. Am J Physiol-Gastr L 277: G922-G928.

28. Rooks MG, Garrett WS (2016) Gut microbiota, metabolites and host immunity. Nat Rev Immunol 16: 341-352.

29. Cammarota G, Ianiro G, Cianci R, Bibbò S, Gasbarrini A, Currò D (2015) The involvement of gut microbiota in inflammatory bowel disease pathogenesis: potential for therapy. Pharmacol Ther 149: 191-212.

30. Bennet JD, Brinkman M (1989) Treatment of ulcerative colitis by implantation of normal colonic flora. Lancet 1:164.

31. Cui M, Xiao H, Li Y, Zhou L, Zhao S, Luo D Zheng Q, Dong J, Zhao Y, Zhang X, Zhang J, Lu L, Wang H, Fan S (2017) Faecal microbiota transplantation protects against radiationinduced toxicity. EMBO Mol Med 9: 448-461.

32. Routy B, Le Chatelier E, Derosa L, Duong CPM, Alou MT, Daillère R, Fluckiger A, Messaoudene M, Rauber C, Roberti MP, Fidelle M, Flament C, Poirier-Colame V, Opolon P, Klein C, Iribarren K, Mondragón L, Jacquelot N, Qu B, Ferrere G, Clémenson C, Mezquita L, Masip JR, Naltet C, Brosseau S, Kaderbhai C, Richard C, Rizvi H, Levenez F, Galleron N, Quinquis B, Pons N, Ryffel, Minard-Colin V, Gonin P, Soria J, Deutsch E, Loriot Y, Ghiringhelli F, Zalcman G, Goldwasser F, Escudier B, Hellmann MD, Eggermont A, Raoult D, Albiges L, Kroemer G, Zitvogel L (2018) Gut microbiome influences efficacy of PD-1-based immunotherapy against epithelial tumors. Science 359: 91-97.

33. Fukuda S, Toh H, Hase K, Oshima K, Nakanishi Y, Yoshimura K, Tobe T, Clarke JM, Topping DL, Suzuki T, Taylor TD, Kikuchi KJ, Morita H, Hattori M, Ohno H (2011) Bifidobacteria can protect from enteropathogenic infection through production of acetate. Nature 469: 543-547.

34. Paramsothy S, Nielsen S, KammMA, Deshpande NP, Faith JJ, Clemente JC, Paramsothy R, Walsh AJ, van den Bogaerde J, Samuel D, Leong RWL, Connor S, Ng W, Lin E, Borody TJ, Wilkins MR, Colombel J, Mitchell HM, Kaakoush NO (2019) Specific bacteria and metabolites associated with response to fecal microbiota transplantation in patients with ulcerative colitis. Gastroenterology 156: 1440-1454.

35. Geirnaert A, Calatayud M, Grootaert C, Laukens D, Devriese S, Smagghe G, De Vos M, Boon N, Van de Wiele T (2017) Butyrate-producing bacteria supplemented in vitro to Crohn's disease patient microbiota increased butyrate production and enhanced intestinal epithelial barrier integrity. Sci Rep 7: 1-14.

36. Borody TJ, Warren EF, Leis S, Surace R, Ashman O (2003) Treatment of ulcerative colitis using fecal bacteriotherapy. J Clin Gastroenterol 37: 42-47.

37. Mathewson ND, Jenq R, Mathew AV, Koenigsknecht M, Hanash A, Toubai T, Oravecz-Wilson K, Wu S, Sun Y, Rossi C, Fujiwara H, Byun J, Shono Y, Lindemans C, Calafiore M, Schmidt TM, Honda K, Young VB, Pennathur S, van den Brink M, Reddy P (2016) Gut microbiome-derived metabolites modulate intestinal epithelial cell damage and mitigate graftversus-host disease. Nat Immunol 17: 505-513.

38. DeFilipp Z, Peled JU, Li S, Mahabamunuge J, Dagher Z, Slingerland AE, Rio CD, Valles B, Kempner ME, Smith M, Brown J, Dey BR, El-Jawahri A, McAfee SL, Spitzer TR, Ballen KK, Sung AD, Dalton TE, Messina JA, Dettmer K, Liebisch G, Oefner P, Taur Y, Pamer EG, Holler E, Mansour MK, van den Brink MRM, Hohmann E, Jenq RR, Chen Y (2018) Thirdparty fecal microbiota transplantation following Allo-HCT reconstitutes microbiome diversity. Blood Adv 2: 745-753.

39. Eckmann L (2005) Defence molecules in intestinal innate immunity against bacterial infections. Curr Opin Gastroenterol 21: $147-151$.

40. Umu ÖCO, Bäuerl C, Oostindjer M, Pope PB, Hernández PE, Pérez- Martínez G, Diep DB (2016) The potential of class II bacteriocins to modify gut microbiota to improve host health. PLoS One 11: 1-22.

41. Horácková Š, Plocková M, Demnerová K (2018) Importance of microbial defence systems to bile salts and mechanisms of serum cholesterol reduction. Biotechnol Adv 36: 682-690.

42. Vandamme D, Landuyt B, Luyten W, Schoofs LA (2012) Comprehensive summary of LL-37, the factotum human cathelicidin peptide. Cell Immunol 280: 22-35.

43. Ridlon JM, Kang DJ, Hylemon PB, Bajaj JS (2014) Bile acids and the gut microbiome. Curr Opin Gastroenterol 30: 332-338.

44. Zhang Z, Mocanu V, Cai C, Dang J, Slater L, Deehan EC, Walter J, Madsen KL (2019) Impact of fecal microbiota transplantation on obesity and metabolic syndrome-a systematic review. Nutrients 11: 11-16.

45. Kang DW, Adams JB, Gregory AC, Borody T, Chittick L, Fasano A, Khoruts A, Geis E, Maldonado J, McDonoughMeans S, Pollard EL, Roux S, Sadowsky MJ, Lipson KS, Sullivan MB, Caporaso JG, Krajmalnik-Brown R (2017) Microbiota transfer therapy alters gut ecosystem and improves gastrointestinal and autism symptoms: an open-label study. Microbiome 5: 1-16.

46. Makkawi S, Camara-Lemarroy C, Metz L (2018) Fecal microbiota transplantation associated with 10 years of stability in a patient with SPMS. Neurol Neuroimmunol Neuroinflammation 5: 1-3.

47. Peng J, Xiao X, HuM, Zhang X (2018) Interaction between gut microbiome and cardiovascular disease. Life Sci 214: 153157.

48. Qi X, Li X, Zhao Y, Wu X, Chen F, Ma X, Zhang F, Wu D (2018) Treating steroid refractory intestinal acute graft-vs.-host disease with fecal microbiota transplantation: a pilot study. Front Immunol 9: 1-7.

49. Minato T, Maeda T, Fujisawa Y, Tsuji H, Nomoto K, Ohno K, Hirayama M (2017) Progression of Parkinson's disease is associated with gut dysbiosis: two-year follow-up study. PLoS One 12: 1-14.

50. Bajaj JS, Kassam Z, Fagan A, Gavis EA, Liu E, Cox IJ, Kheradman R, Heuman D, Wang J, Gurry T, Williams R, Sikaroodi M, Fuchs M, Alm E, John B, Thacker LR, Riva A, Smith M, Taylor-Robinson SD, Gillevet PM (2017) Fecal microbiota transplant from a rational stool donor improves hepatic encephalopathy: a randomized clinical trial. Hepatology 66: 1727-1738.

51. Zhou D, Pan Q, Shen F, Cao H-X, Ding W-J, Chen Y-W, Fan J (2017) Total fecal microbiota transplantation alleviates highfat diet-induced steatohepatitis in mice via beneficial regulation of gut microbiota. Sci Rep 7: 1-11. 
52. DeFilipp Z, Bloom PP, Soto MT, Mansour MK, Sater MRA, Huntley MH, Turbett S, Chung RT, Chen YB, Hohmann EL (2019) Drug-resistant E. coli bacteremia transmitted by fecal microbiota transplant. N Engl J Med 381: 2043-2050. doi: 10.1056/NEJMoa1910437.

53. Edelstein C, Daw JR, Kassam Z (2016) Seeking safe stool: Canada needs a universal donor model. CMAJ 188: E431E432.

54. Kim KO, Schwartz M, Gluck M (2019) Reducing cost and scheduling complexity of fecal microbiota transplantation by using universal donor over patients-directed donors in patients with recurrent Clostrodium difficile infections. Adv Ther 36: 2052-2061.

55. OpenBiome (2017) OpenBiome quality \& safety program. Cambridge (MA): OpenBiome; c2017. Available from: https://www.openbiome.org/safety. Accessed on12/12/19.

56. Jiang ZD, Ajami NJ, Petrosino JF, Jun G, Hanis CL, Shah M, Hochman L, Ankoma-Sey V, DuPont AW, Wong MC, Alexander A, Ke S, DuPont HL (2017) Randomised clinical trial: faecal microbiota transplantation for recurrent Clostridium difficile infection - fresh, or frozen, or lyophilised microbiota from a small pool of healthy donors delivered by colonoscopy. Aliment Pharmacol Ther 45: 899-908.

57. Choi HH, Cho YS (2016) Fecal microbiota transplantation: Current applications, effectiveness, and future perspectives. Clin Endosc 49: 257-265.

58. Cammarota G, Ianiro G, Tilg H, Rajilic-Stojanovic M, Kump P, Satokari R, Sokol H, Arkkila P, Pintus C, Hart A, Segal J, Aloi M, Masucci L, Molinaro A, Scaldaferri F, Gasbarrini G, Lopez-Sanroman A, Link A, de Groot P, de Vos WM, Högenauer C, Malfertheiner P, Mattila E, Milosavljević T, Nieuwdorp M, Sanguinetti M, Simren M, Gasbarrini A (2017) European consensus conference on faecal microbiota transplantation in clinical practice. Gut 66: 569-580.

59. Kernbauer E, Ding Y, Cadwell K (2014) An enteric virus can replace the beneficial function of commensal bacteria. Nature 516: 94-98.
60. Hota SS, McNamara I, Jin R, Kissoon M, Singh S, Poutanen SM (2019) Challenges establishing a multi-purpose fecal microbiota transplantation stool donor program in Toronto, Canada. JAMMI 4: 218-226.

61. Cui B, Feng Q, Wang H, Wang M, Peng Z, Li P, Huang G, Liu Z, Wu P, Fan Z, Ji G, Wang X, Wu K, Fan D, Zhang F (2015) Fecal microbiota transplantation through mid-gut for refractory Crohn's disease: safety, feasibility, and efficacy trial results. J Gastroenterol Hepatol 30: 51-58.

62. Dai Z, Zhang J, Wu Q, Chen J, Liu J, Wang L, Chen C, Xu J, Zhang H, Shi C, Li Z, Fang H, Lin C, Tang D, Wang D (2019) The role of microbiota in the development of colorectal cancer. Int J Cancer 145: 2032-2041.

63. Wong SH, Zhao L, Zhang X, Nakatsu G, Han J, Xu W, Xiao X, Kwong TNY, Tsoi H, Wu WKK, Zeng B, Chan FKL, Sung JJY, Wei H, Yu J (2017) Gavage of fecal samples from patients with colorectal cancer promotes intestinal carcinogenesis in germ-free and conventional mice. Gastroenterology 153: 16211633.

64. Baxter M, Ahmad T, Colville A, Sheridan R (2015) Fatal aspiration pneumonia as a complication of fecal microbiota transplant. Clin Infect Dis 61: 136-137.

65. Hsu WH, Wang JY, Kuo CH (2019) Current applications of fecal microbiota transplantation in intestinal disorders. Kaohsiung J Med Sci 35: 327-331.

\section{Corresponding author}

Muluneh Ademe, (MSc)

Department of Microbiology, Immunology and Parasitology, College of Health Sciences

Addis Ababa University, P.O. Box 9086

Addis Ababa, Ethiopia.

Phone: +251 15513099

Email: muluneh.ademe@aau.edu.et

Conflict of interests: No conflict of interests is declared. 